Article

\title{
Brazilian Green Propolis Extract Synergizes with Protoporphyrin IX-mediated Photodynamic Therapy via Enhancement of Intracellular Accumulation of Protoporphyrin IX and Attenuation of NF-KB and COX-2
}

\author{
Cheng-Cheng Wang ${ }^{1,+}$, Yu-Xuan Wang ${ }^{2,+}$, Nian-Qin $\mathrm{Yu}^{3}$, Die Hu ${ }^{3}$, Xiao-Yan Wang ${ }^{3}$, \\ Xing-Guang Chen ${ }^{3}$, You-Wei Liao ${ }^{3}$, Jing Yao ${ }^{3,4,5}$, Hao Wang ${ }^{3,4}, 5$, Ling He ${ }^{6, *}$ and Liang Wu ${ }^{3, *}$ \\ 1 School of Pharmacy, China Pharmaceutical University, Nanjing 210009, China; w940984614@hotmail.com \\ 2 School of Life Science and Technology, China Pharmaceutical University, Nanjing 210009, China; \\ w597507666@hotmail.com \\ 3 Jiangsu Key Laboratory of Drug Screening, China Pharmaceutical University, Nanjing 210009, China; \\ shizi14tian@163.com (N.-Q.Y.); hudiesunny@outlook.com (D.H.); wxy94@hotmail.com (X.-Y.W.); \\ starlight_c@outlook.com (X.-G.C.); lyw0206031@hotmail.com (Y.-W.L.); yaoyaossnh@163.com (J.Y.); \\ wanghao@cpu.edu.cn (H.W.) \\ 4 State Key Laboratory of Natural Medicines, China Pharmaceutical University, Nanjing 210009, China \\ 5 Department of Natural Medicinal Chemistry, China Pharmaceutical University, Nanjing 210009, China \\ 6 Department of Pharmacology, China Pharmaceutical University, Nanjing 210009, China \\ * Correspondence: hexyz@163.com (L.H.); 1020132373@cpu.edu.cn (L.W.); Tel.: +86-258-327-1099 (L.W.) \\ $\dagger$ These authors contributed equally to this work and should be considered co-first authors.
}

Academic Editor: Thomas J. Schmidt

Received: 7 March 2017; Accepted: 28 April 2017; Published: 4 May 2017

\begin{abstract}
Brazilian green propolis (BGP) is noted for its impressive antitumor effects and has been used as a folk medicine in various cultures for many years. It has been demonstrated that BGP could enhance the cytotoxic effect of cytostatic drugs on tumor cells. Photodynamic therapy (PDT) is a therapeutic approach used against malignant cells. To assess the synergistic effect of BGP extract on protoporphyrin IX (PpIX)-mediated photocytotoxicity, MTT assays were performed using A431 and HeLa cells. TUNEL assay and Annexin V-FITC/PI staining were performed to confirm the induction of apoptosis. Western blotting analysis was performed to examine the pro-apoptotic proteins, anti-apoptotic proteins and inflammation related proteins in A431 cells. Intracellular accumulation of PpIX was examined by flow cytometry. The synergistic effect of BGP extract in PpIX-PDT was also evaluated with a xenograft model. Our findings reveal that BGP extract increased PpIX-mediated photocytotoxicity in A431 and HeLa cells. PpIX-PDT with BGP extract treatment resulted in a decrease in Bcl-xL and an increase in NOXA, Bax and caspase- 3 cleavage. The protein expression levels of $\mathrm{p}-\mathrm{IKK} \alpha / \beta, \mathrm{NF}-\mathrm{\kappa B}$ and COX-2 were upregulated by PpIX-PDT but significantly attenuated when in combination with BGP extract. BGP extract was also found to significantly enhance the intracellular accumulation of PpIX in A431 cells. BGP extract increased PpIX-mediated photocytotoxicity in a xenograft model as well. Our findings provide evidence for a synergistic effect of BGP extract in PpIX-PDT both in vitro and in vivo.
\end{abstract}

Keywords: Brazilian green propolis; synergy; photodynamic therapy; cancer; inflammation; apoptosis 


\section{Introduction}

As a natural product, propolis has been known and used as a traditional folk medicine in various cultures for thousands of years. It is composed mainly of wax and resins. The latter are derived from plants and contain substances with biological activity. The composition of propolis is variable, and many plant substances have been identified for the first time in propolis [1].

Due to the rich and diverse flora in Brazil, propolis samples collected from this country show distinct colors and chemical compositions depending on the local flora at the site of collection [2]. Brazilian Green Propolis (BGP) is collected from the Minas Gerais region of Brazil. This region is home to a unique plant species, Baccharis dracunculifolia D.C., which produces the best grade of propolis with the highest level of flavonoids and artepillin C. The Africanized honeybee from this region can produce propolis from the unexpanded leaf buds of Baccharis dracunculifolia D.C. plant. Only this bee species has the capacity to produce BGP with concentrated artepillin C, a powerful constituent not found in propolis from other regions.

BGP has been reported to have a wide range of biological properties including anti-bacterial [3], anti-inflammatory [4-7], anti-hypertensive [8,9], anti-hyperlipidemic [10], antioxidant [11] and antitumor [12-17] activities. BGP was shown to suppress the hypoxia-induced inflammatory responses through inhibition of the nuclear factor-kappa B (NF-kB) activation in microglia [7]. Artepillin C, a specific bioactive component of BGP, was shown to decrease the activity of NF- $\mathrm{KB}$ and potentiate the tumor necrosis factor (TNF)-related apoptosis on LNCaP prostate cancer cells [17]. Additionally, an ethanolic extract of BGP was reported to sensitize prostate cancer cells to tumor necrosis factor-related apoptosis-inducing ligand (TRAIL)-induced apoptosis [16].

Photodynamic therapy (PDT) is a clinically approved therapeutic approach that can exert selective cytotoxic activity against malignant cells. Classical PDT involves the administration of two individually non-toxic components: a photosensitizing agent followed by illumination with a laser which has a wavelength specific to the absorbance band of the photosensitizer. Most of the photosensitizers used in cancer therapy are tetrapyrroles, similar to that of the protoporphyrin contained in hemoglobin [18]. As a classic photosensitizer, protoporphyrin IX has been widely used in PDT.

It has been established that PDT could induce inflammation. Elevated levels of inflammationrelated molecules within PDT-targeted tissue, such as NF-kB and cyclooxygenase-2 (COX-2), could reduce the antitumor effectiveness of PDT by facilitating survival of residual tumor cells, [18-22]. $\mathrm{NF}-\mathrm{kB}$ is a major transcription factor that regulates various cell processes, such as apoptosis, inflammation, proliferation, angiogenesis and immunity [23]. COX-2 is overexpressed in many types of cancer and is considered to be associated with reduced patient survival [24]. It has been reported that increased NF-KB and COX-2 expression are some of the molecular factors that contribute to tumor recurrence $[18,25,26]$. Therefore, inhibiting NF- $\mathrm{kB}$ or COX-2 activation might be strategies to improve the tumoricidal efficiency of PDT. It has been demonstrated that dihydroartemisinin enhanced PDT-induced growth inhibition and apoptosis via deactivating PDT-induced NF- $\mathrm{kB}$ activation [27]. Furthermore, blockage of COX-2 expression has been shown to facilitate PDT-induced apoptosis [28].

Given its impressive antitumor and anti-inflammatory properties, our study investigates the synergistic effect of BGP extract in PpIX-mediated PDT (PpIX-PDT) both in vitro and in vivo, and explores its potential mechanisms.

\section{Results}

\subsection{Phytochemical Analysis of Extracts of BGP by HPLC-UV}

The chemical composition of the BGP extract was analyzed by HPLC-UV and a total ion current chromatogram. The content of $p$-coumaric acid (1), quercetin (2) and artepillin C (3) in BGP extracts was about $2.26 \mathrm{mg} / \mathrm{g}, 2.17 \mathrm{mg} / \mathrm{g}$ and $8.23 \mathrm{mg} / \mathrm{g}$, respectively (Figure 1). 
(a)

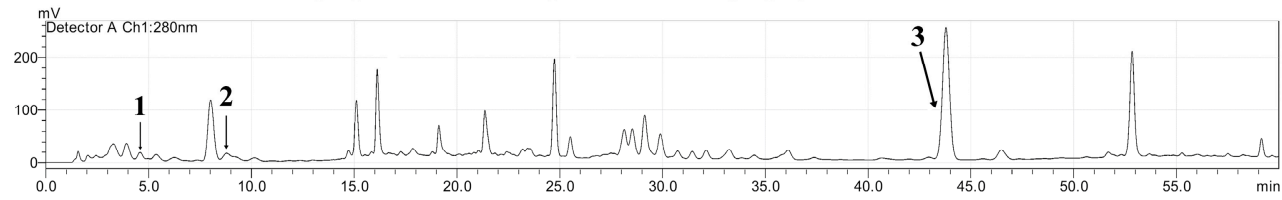

(b) Total ion current chromatogram of BGP extract

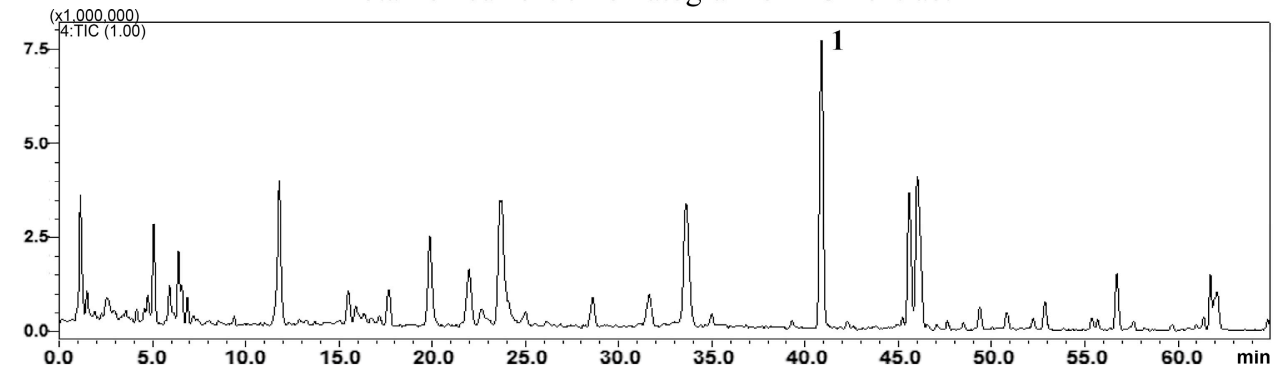

Figure 1. (a) HPLC chromatogram of Brazilian green propolis (BGP) extract. (1: $p$-coumaric acid, Rt: 4.86 min; 2: quercetin, Rt: $8.65 \mathrm{~min}$ 3: artepillin C, Rt: $44.0 \mathrm{~min}$ ) (b) LC-IT-TOF-MS total ion current chromatogram (TIC) of BGP extract in the negative ion mode. 1: artepillin C, Rt: $42.0 \mathrm{~min}$ (PubChem CID 5472440).

\subsection{BGP Extract Increased P PIX-mediated Photocytotoxicity through Induction of Apoptosis}

To assess the synergistic effect of BGP extract on PpIX-mediated photocytotoxicity, MTT assays were performed using A431 and HeLa cells. In the presence of different BGP extract dosages (62.5 and $75 \mu \mathrm{g} / \mathrm{mL}$ ), the cell toxicity of A431 cells after PpIX-PDT exposure (PpIX = 1.8, 2.7 and $4.0 \mu \mathrm{M}$ ) is shown in Figure 2a.

(a)

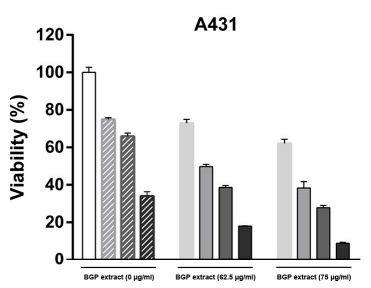

A431

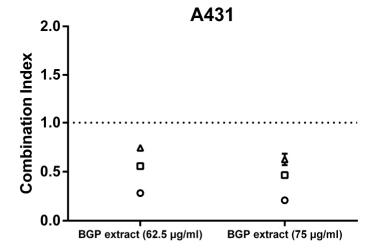

(b)

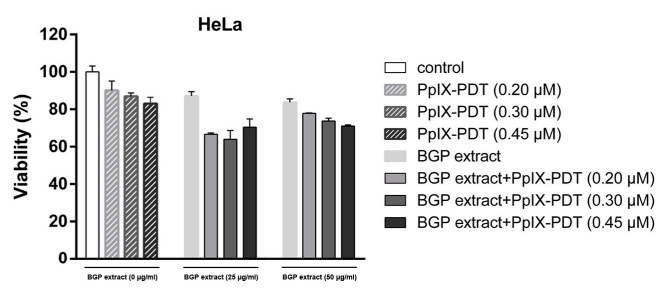

HeLa

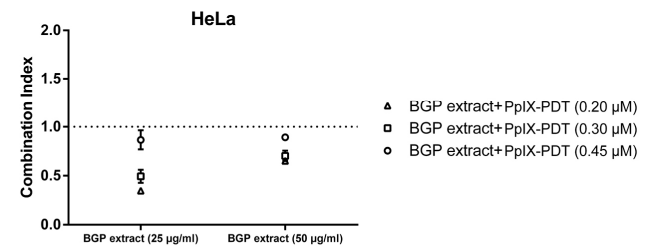

Figure 2. Brazilian green propolis (BGP) extract enhanced protoporphyrin IX (PpIX)-mediated photocytotoxicity in vitro. Combined effects of BGP extract and PpIX-mediated PDT (PpIX-PDT) in A431 and HeLa cells were tested by MTT according to the methods described above. (a) A431 cells were incubated with several PpIX concentrations $(1.8,2.7$ and $4.0 \mu \mathrm{M})$ employing the BGP extract (62.5 and $75 \mu \mathrm{g} / \mathrm{mL}$ ); (b) For HeLa cells, the concentrations of PpIX were 0.20, 0.30 and $0.45 \mu \mathrm{M}$ employing the BGP extract ( 25 and $50 \mu \mathrm{g} / \mathrm{mL}$ ). All groups were illuminated by laser. Results were expressed as viability relative to the control. The combination index (CI) corresponded with the data of viability. $\mathrm{CI}$ is a quantitative measure of the degree of drug interaction in terms of additive effect $(\mathrm{CI}=1)$, synergism $(\mathrm{CI}<1)$, or antagonism $(\mathrm{CI}>1)$. Data were expressed as mean $\pm \mathrm{SEM}$ of three independent experiments. 
$48 \mathrm{~h}$ after illumination, a significant increase of cell toxicity could be observed in the combination group, compared with the BGP extract or PpIX-PDT alone group (Figure 2a). Similar results were observed on HeLa cells in Figure $2 b$ (BGP extract $=25$ and $50 \mu \mathrm{g} / \mathrm{mL}, \mathrm{PpIX}=0.20,0.30$ and $0.45 \mu \mathrm{M}$ ). The CI values indicated a synergistic enhancement of cytotoxicity in both cells (Figure 2). As $75 \mu \mathrm{g} / \mathrm{mL}$ BGP extract resulted in a significant enhancement of PpIX-PDT-induced cytotoxicity in A431 cells, we adopted $75 \mu \mathrm{g} / \mathrm{mL}$ BGP extract combined with PpIX-PDT in the subsequent analyses.

A TUNEL assay was performed to further confirm the induction of apoptosis by BGP extract on PpIX-mediated photocytotoxicity. As shown in Figure 3, only the combination group exhibited FITC positive signal (green) while the individual treatments were negative, suggesting an enhanced induction of apoptosis by BGP extract in PpIX-PDT. The synergistic effect was further demonstrated by Annexin V-FITC/PI staining (Figure 4), confirming the induction of apoptosis.

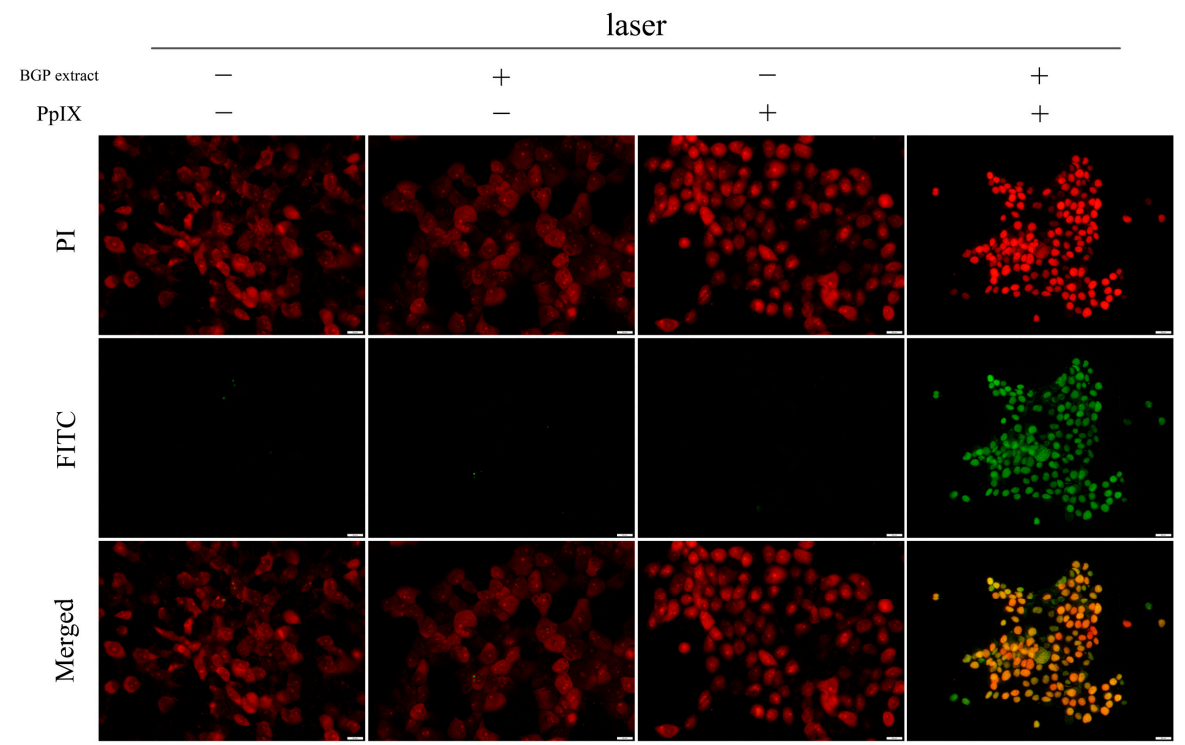

Figure 3. Apoptotic detection by TUNEL assay. PI (red) stained the nucleus while FITC (green) labeled the apoptotic cells. Images were captured by a confocal scanning laser microscope. Scale bar: $50 \mu \mathrm{m}$.

(a)

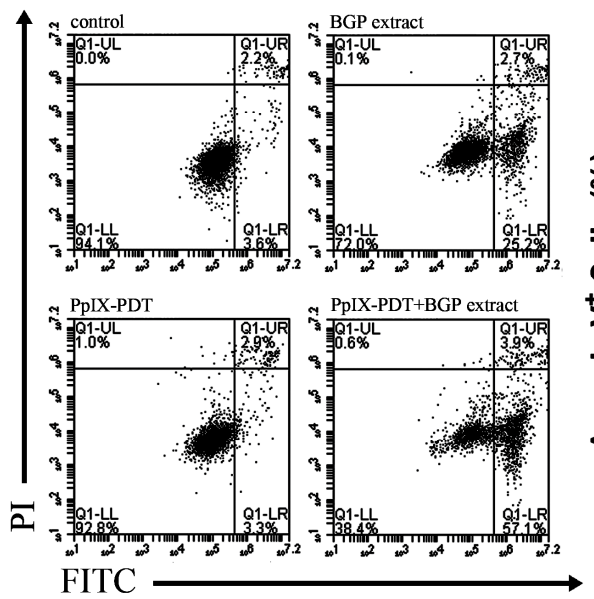

(b)

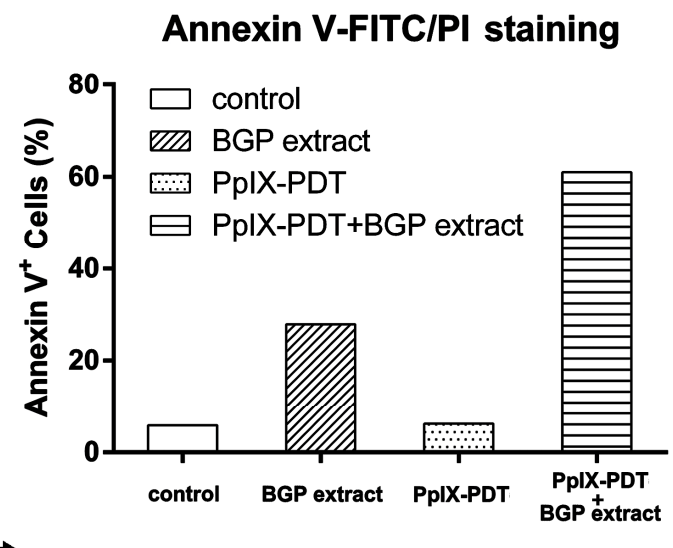

Figure 4. Annexin V-FITC/PI staining of A431 cells. (a) Cells were treated with or without Brazilian green propolis (BGP) extract in protoporphyrin IX-mediated photodynamic therapy (PpIX-PDT) and stained using Annexin V-FITC/PI staining assay before detection by a BD Accuri ${ }^{\mathrm{TM}}$ C6 flow cytometer. All groups were illuminated by laser; (b) The percentages of apoptotic cells. 
To investigate the mechanism of BGP extract induced synergistic enhancement of apoptosis in PpIX-PDT, western blotting analysis was performed to examine the pro-apoptotic proteins (Bax, NOXA and cleaved-caspase-3) and anti-apoptotic protein (Bcl-xL) in A431 cells. When cells were treated with PpIX-PDT, upregulation of Bax and NOXA were induced, while the level of Bcl-xL was unchanged (Figure 5). PpIX-PDT with BGP extract treatment resulted in a decrease in Bcl-xL and an increase in NOXA and Bax in comparison with PpIX-PDT alone treatment (Figure 5). Furthermore, cleaved caspase-3 significantly increased in the combination group compared to the controls, indicating the enhanced activation of apoptotic pathway (Figure 5).
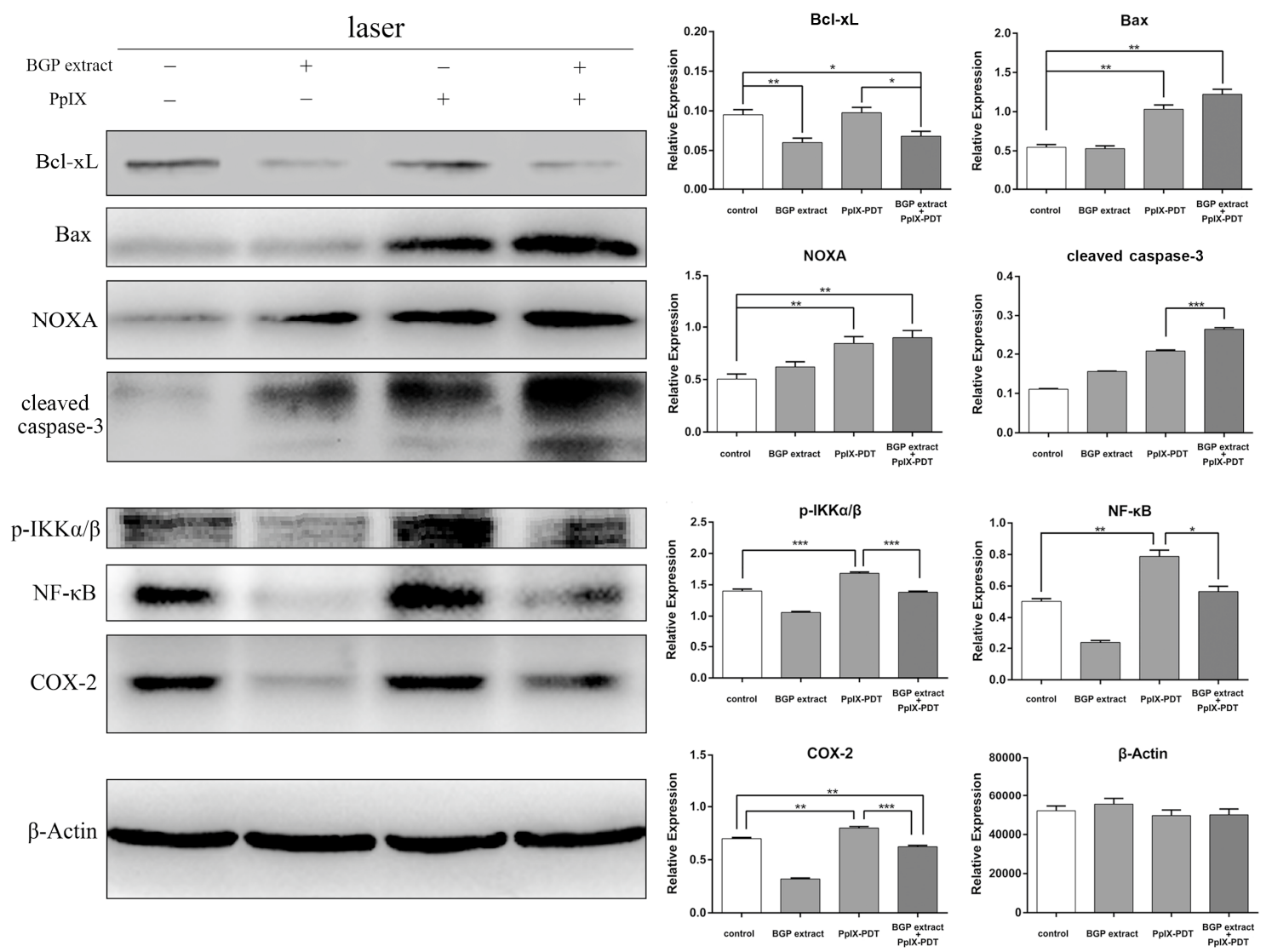

Figure 5. Apoptosis and NF- $\mathrm{kB}$-related proteins expression. Western blotting analysis of the expression of Bcl-xL, Bax, NOXA, cleaved-caspase-3, p-IKK $\alpha / \beta$, NF- $\mathrm{kB}$ and COX-2, from cell homogenates, with $\beta$-Actin as a protein loading control. All groups were illuminated by laser. Data represent mean \pm SEM $(n=3) .{ }^{*} p<0.05,{ }^{* *} p<0.01,{ }^{* * *} p<0.001$.

\subsection{BGP Extract Attenuated PDT-Mediated Elevation of NF- $\kappa B$ and COX-2}

PDT could induce NF- $\mathrm{kB}$ activation, thereby playing a negative role in the induction of apoptosis. Knowing that propolis could inhibit NF- $\mathrm{kB}$ activity, we set out to investigate if BGP extract could enhance the anti-tumor effect of PpIX-PDT on A431 cells via inhibition of NF-kB. Western blotting analysis was performed to examine NF- $\mathrm{kB}$ related protein and its downstream proteins expression in A431 cells. The protein expression levels of $\mathrm{p}-\mathrm{IKK} \alpha / \beta, \mathrm{NF}-\mathrm{KB}$ and COX-2 were upregulated by PpIX-PDT but significantly attenuated when in combination with BGP extract (Figure 5) indicating that BGP extract reduced PpIX-PDT induced inflammation.

\subsection{BGP Extract Enhanced the Anti-tumorigenicity of PpIX-PDT in a Xenograft Model}

To further assess the synergistic effect of BGP extract and PpIX-PDT, in vivo tumorigenicity after PDT pretreatment was assayed. As shown in Figure 6, six days after inoculation of the pretreated 
A431 cells, the body weight of the control group decreased while in other groups it kept steady. As expected, the tumor volume was lowest with BGP extract-treated A431 cells following PpIX-PDT; while BGP extract treatment or PpIX-PDT alone did not affect tumor growth in BALB/c-nu mice (Figure 6). Subsequently, the tumor burdens were measured. The results showed that the tumors in BGP extract-combined PpIX-PDT group were significantly distributed in lower tumor volume ranges compared with BGP extract group, PpIX-PDT alone group or the control group (Figure 6). The tumor weight was also decreased in the BGP extract-combined PpIX-PDT group (Figure 6). These results were consistent with the findings of the in vitro assays.

(a)

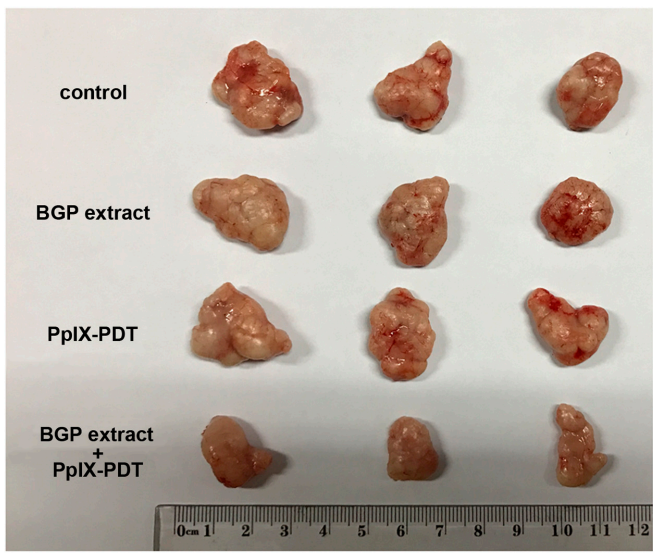

(c)

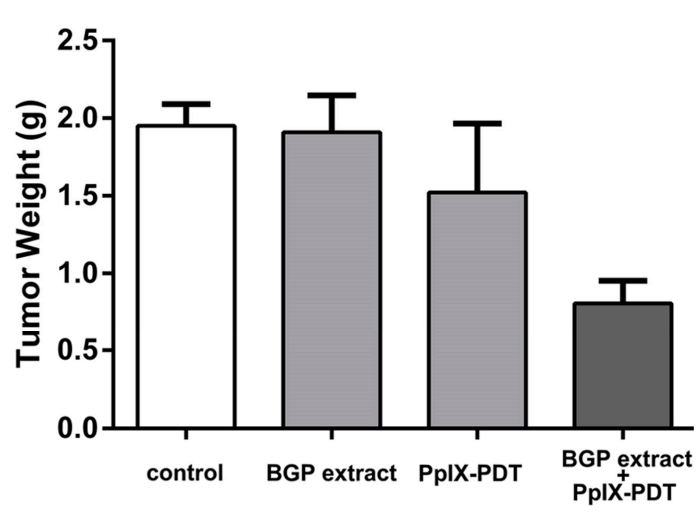

(b)

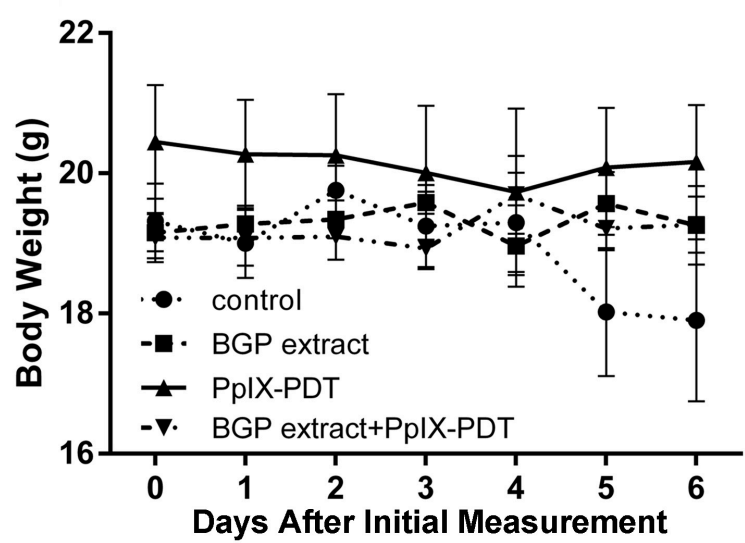

(d)

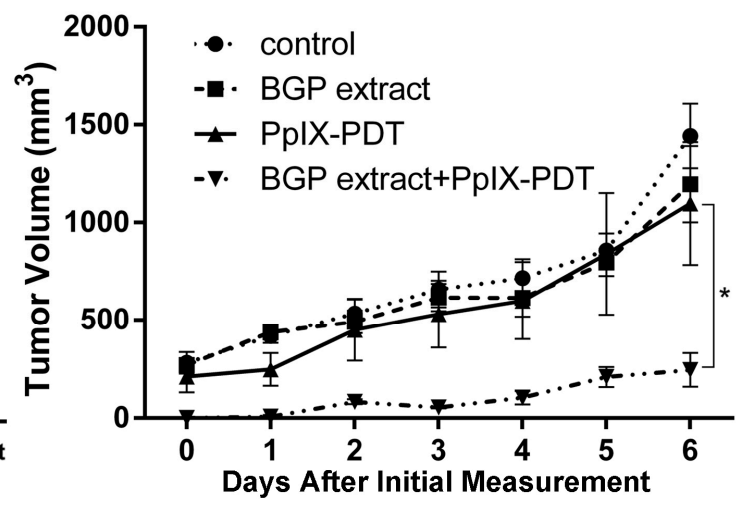

Figure 6. Brazilian green propolis (BGP) extract enhanced the anti-tumorigenicity of protoporphyrin IX-mediated photodynamic therapy (PpIX-PDT) in a BALB/c-nu mice xenograft model. A total of $3 \times 10^{6}$ A431 cells, pretreated with BGP extract $(75 \mu \mathrm{g} / \mathrm{mL})$ and PpIX-PDT $(2.7 \mu \mathrm{M})$, either alone or in combination, were implanted subcutaneously into BALB/c-nu mice ( 6 per group). All groups were illuminated by laser. (a) The representative images of tumors after two-week development; (b,d) Body weight and tumor volume $\left({ }^{*} p<0.05\right)$ of mice were measured once per day after one-week development; (c) Mice were sacrificed 2 weeks after implantation and tumor weight was measured.

\subsection{BGP Extract Increased Intracellular Accumulation of PpIX in PDT}

To further investigate the synergetic mechanisms of BGP extract in PpIX-PDT, the intracellular accumulation of PpIX was examined by flow cytometry based on the fluorescence property of PpIX. Cells were treated with either PpIX or PpIX combined with BGP extract as described above. BGP extract was found to significantly enhance the intracellular accumulation of PpIX in A431 cells as a 
much higher PpIX specific fluorescence could be observed on the combination group compared to that of the PpIX group (Figure 7).

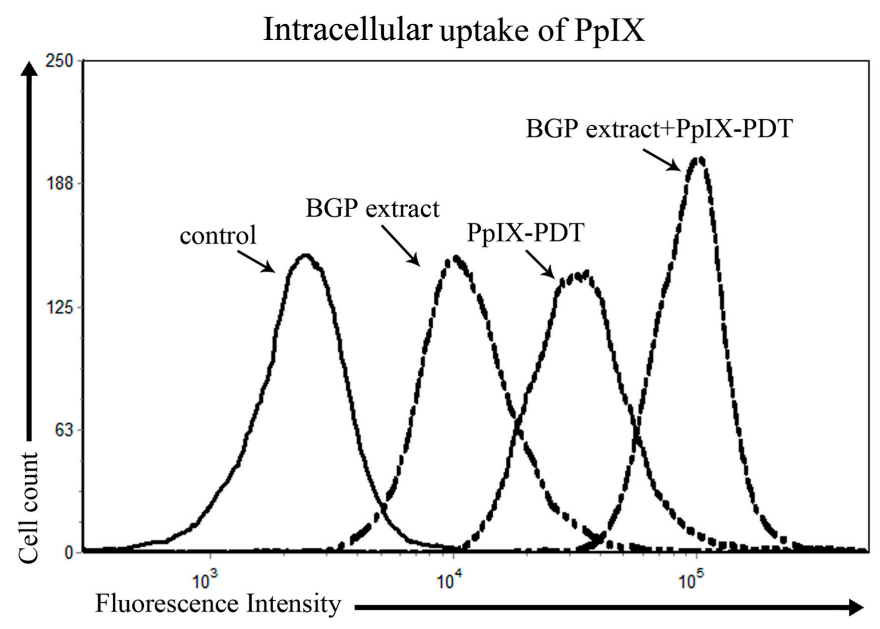

Mean Fluorescence Intensity

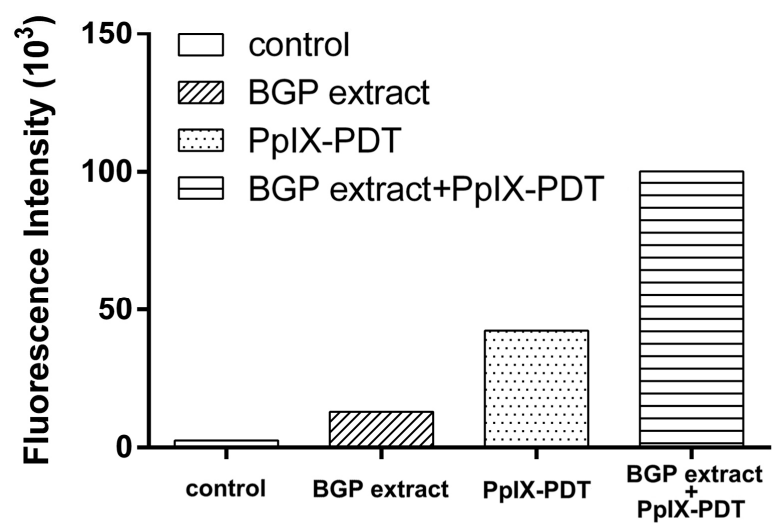

Figure 7. Intracellular accumulation detection of protoporphyrin IX (PpIX) by flow cytometry. Mean fluorescence intensity was measured by a BD Accuri ${ }^{\mathrm{TM}} \mathrm{C} 6$ flow cytometer.

\section{Discussion}

Previously, propolis has been shown to augment the effect of chemotherapy on various cancers [16,29-31]. In this study we have investigated the synergistic effect of BGP extract on PpIX-PDT. Our findings show that BGP extract significantly synergizes with PpIX-PDT both in A431 and HeLa cells. Result in vivo is consistent with that in vitro. BGP extract increased the susceptibility of the cancer cells to apoptosis upon PDT via decreasing the anti-apoptotic protein $(\mathrm{Bcl}-\mathrm{xL})$ and increasing the pro-apoptotic proteins (Bax, NOXA and cleaved caspase-3), which indicates that BGP extract enhanced PDT-induced death through the pathways associated with mitochondrial damage.

PDT induced ROS may lead to enhanced IKK $\alpha / \beta$ phosphorylation which is an indication of NF- $\mathrm{KB}$ activation. It was demonstrated that NF- $\mathrm{kB}$ was activated upon verteporfin-mediated photosensitization in a promyelocytic cell line (HL-60 cells) [32]. An increase of NF-kB activity was demonstrated in HT-29 adenocarcinoma cells after hypericin-mediated photosensitization [33]. Korbelik has shown activation of NF-KB in photofrin-mediated PDT in a mouse SCCVII tumor model [34]. Consistent with the abovementioned studies, we found that PpIX-PDT could induce NF-kB activation in A431 cells. Since activation of NF- $k B$ after PDT supports the survival of tumor cells 
by preventing apoptosis [35], pharmacological interventions in the NF- $\mathrm{KB}$ pathway might improve PDT outcomes.

We have explored the modulation of NF- $\mathrm{kB}$ pathway in PpIX-PDT upon BGP extract treatment due to its excellent antitumor activity and its unique capacity to inhibit NF- $\mathrm{KB}$. As expected, we found that BGP extract attenuated the upregulation of $\mathrm{p}-\mathrm{IKK} \alpha / \beta$ and NF-KB induced by PpIX-PDT.

Agents targeting COX-2 were considered as adjuvants for PDT [28] as elevated levels of COX-2 were shown to decrease the efficiency of tumor treatment [36,37]. It has been reported that, combing PDT with celecoxib, a selective COX-2 inhibitor, decreased the expression of inflammatory and angiogenic factors which are frequently associated with tumor recurrence [28]. Previously, Hypericin mediated PDT in T24 and HeLa cells was shown to strongly activate the expression of COX-2 [38]. Consistent with previous findings, we found that PpIX-PDT increased the level of COX-2 whereas BGP extract clearly attenuated the induction of COX-2 by PpIX-PDT. This reduced COX-2 expression might be due to the inhibition of NF- $\mathrm{kB}$ by BGP extract because the promoter sequence of COX-2 contains binding sites for NF- $\mathrm{KB}$, making it a downstream target of NF- $\mathrm{KB}$ [39-41]. It was reported that silencing COX-2 promotes NOXA expression [28], which is consistent with our findings that BGP extract treatment elevated NOXA expression in PpIX-PDT following COX-2 downregulation.

The tumor-selective effects of the PDT are based on the preferential uptake and retention of the photosensitizer in the tumor [42]. The intracellular uptake and accumulation of photosensitizers has been a major problem in PDT especially when treating large solid tumors [43,44]. Our results demonstrate for the first time that BGP extract increases intracellular accumulation of PpIX in cancer cells during PDT which might be another important mechanism of the synergistic effect.

Although the tumorigenic potential of cancer cells pre-treated with BGP and PDT in vitro was evaluated with a xenograft model in the present study, further in vivo studies will be necessary to demonstrate the therapeutic usefulness of BGP on PDT as our current findings dose not yet represent a proof of a true therapeutic potential.

\section{Materials and Methods}

\subsection{Chemicals and Reagents}

PpIX and 3-(4,5-dimethyl-2-thiazolyl)-2,5-diphenyl-2H-tetrazolium bromide (MTT) were purchased from Sigma-Aldrich (Darmstadt, Germany). TUNEL FITC Apoptosis Detection Kit was purchased from Vazyme Biotech Co., Ltd. (Nanjing, China). Annexin V-FITC/PI Apoptosis Kit was purchased from Invitrogen (Waltham, MA, USA). Antibodies against Bcl-xL, Bax, NOXA, cleaved caspase-3, p-IKK $\alpha / \beta, N F-\kappa B$, and anti-rabbit IgG HRP-linked antibody were purchased from Cell Signaling Technology (Danvers, MA, USA). Anti-COX-2 was purchased from Abcam (Cambridge, UK). Mouse anti- $\beta$-actin monoclonal antibody was purchased from Sigma-Aldrich. Polyclonal goat anti-mouse immunoglobulins/HRP was purchased from DAKO (Santa Clara, CA, USA).

\subsection{Preparation of BGP Extract}

The BGP sample was obtained from Royal Natural Product Co. (Markham, ON, Canada). The raw material was collected in Minas Gerais, Brazil. The raw BGP $(5.0 \mathrm{~g})$ were powdered and extracted with $70 \%$ ethanol twice $(500,400 \mathrm{~mL})$ at room temperature for $4 \mathrm{~h}$. After filtration, the ethanol extracts were combined and concentrated under reduced pressure to afford a residue (4.0 g).

\subsection{HPLC Analysis of BGP Extract}

The samples were analyzed using a LC system (Shimadzu, Kyoto, Japan) consisting of a LC-20AT binary pump, SPD-20A detector, SIL-20AC autosampler and a CTO-20AC column oven. The compounds in BGP extract were determined by HPLC-UV with a Shim-pack VP-ODS column $(2.0 \mathrm{~mm} \times 150 \mathrm{~mm}, 5 \mu \mathrm{m}$, Shimadzu). The separation was employed using $0.2 \%$ formic acid in water (A), and acetonitrile (B). A gradient elution was applied (0 min, 15\% B; $5 \mathrm{~min}, 30 \% \mathrm{~B} ; 35 \mathrm{~min}, 45 \%$ B; 
$45 \mathrm{~min}, 65 \% \mathrm{~B} ; 55 \mathrm{~min}, 80 \% \mathrm{~B} ; 60 \mathrm{~min}, 95 \% \mathrm{~B}$.), at the flow rate of $0.3 \mathrm{~mL} / \mathrm{min}$. The injection volume was $10 \mu \mathrm{L}$, and the detection monitored at $280 \mathrm{~nm}$. Peaks were identified, and quantified by external standard methods. The concentrated extract was dissolved in pure methanol solution at concentration level of $60 \mu \mathrm{g} / \mathrm{mL}$, and then filtered through a $0.2 \mu \mathrm{m}$ filter before HPLC analysis.

\subsection{ESI-IT-TOF-MS Analysis of BGP Extract}

MS analyses were performed using the LC-IT-TOF-MS equipped with an ESI source in negative ionization mode. The MS conditions were used as follows: detector voltage, $1.60 \mathrm{kV}$; nebulizing gas $\left(\mathrm{N}_{2}\right)$ flow, $1.5 \mathrm{~L} / \mathrm{min}$; dry gas $\left(\mathrm{N}_{2}\right)$ pressure, $121.0 \mathrm{kPa}$; curved desolvation line $(\mathrm{CDL})$ temperature $200{ }^{\circ} \mathrm{C}$; block temperature $200{ }^{\circ} \mathrm{C}$; ion trap pressure, $1.6 \times 10^{-2}$; TOF pressure, $1.3 \times 10^{-4} \mathrm{~Pa}$; scan range, $m / z$ 100-1000 for $\mathrm{MS}^{1}, 100-800$ for $\mathrm{MS}^{2}$ and 50-500 for $\mathrm{MS}^{3}$; ion accumulated time was set at $30 \mathrm{~ms}$ for $\mathrm{MS}^{1}, 50 \mathrm{~ms}$ for $\mathrm{MS}^{2}, 70 \mathrm{~ms}$ for $\mathrm{MS}^{3}$; the collision energy was set at 50\% for $\mathrm{MS}^{2}$ and, 30\% for $\mathrm{MS}^{3}$. All the operations and data analysis were performed using Shimadzu LC-IT-TOF-MS solution version 3.6 and the Shimadzu Formula Predictor 1.2 was used to establish the molecular formulas.

\subsection{Cell lines and Culture Conditions}

Human epidermoid carcinoma cells, A431 and human cervical cancer cells, HeLa, purchased from KeyGen Biotech. Co., Ltd. (Nanjing, China), were cultured in Dulbecco's modified eagle medium (DMEM) supplemented with 10\% fetal bovine serum (FBS), 50 units $/ \mathrm{mL}$ penicillin and $50 \mu \mathrm{g} / \mathrm{mL}$ streptomycin in $5 \% \mathrm{CO}_{2}$ at $37{ }^{\circ} \mathrm{C}$

\subsection{MTT Assay}

MTT assays were carried out to investigate the enhanced phototoxicity of PpIX-PDT combined with BGP extract on A431 and HeLa cells. Cells were first seeded to 96-well plates as 6000 cells/well. After $12 \mathrm{~h}$, medium containing BGP extract was administrated to cells and allowed to co-incubate for another $12 \mathrm{~h}$. Then a series concentration of PpIX were added accordingly and allowed to co-incubate for $5 \mathrm{~h}$. Afterwards, plates were illuminated by a $450 \mathrm{~nm}$ laser (Banglei Photoelectronic Technology Co., Ltd., Zhongshan, China) at a power of $27 \mathrm{~mW} / \mathrm{cm}^{2}$ for $30 \mathrm{~min}$. The control was run in parallel. Subsequently, cells were incubated in $5 \% \mathrm{CO}_{2}$ at $37^{\circ} \mathrm{C}$ for another $48 \mathrm{~h}$ before MTT was added. After $6 \mathrm{~h}$ incubation, optical density (OD) was monitored at $570 \mathrm{~nm}$ by a microplate reader. Cell viability was calculated as a percentage of viable cells in drug-treated group versus untreated control by the following equation: cell viability $(\%)=(\mathrm{OD}($ treated $)-\mathrm{OD}($ blank $)) /(\mathrm{OD}(\mathrm{control})-$ $\mathrm{OD}($ blank $)) \times 100 \%$.

\subsection{Evaluating the Interaction between BGP Extract and PpIX-PDT}

The combination index $(\mathrm{CI})$ is a quantitative measure of the degree of drug interaction in terms of additive effect $(C I=1)$, synergism $(C I<1)$, or antagonism $(C I>1)$ for a given endpoint of the effect measurement calculated by CalcuSyn v2.

\subsection{TUNEL Assay}

A431 cells were first seeded onto confocal petri dishes for 5000 cells per Petri dish. After $12 \mathrm{~h}$, medium containing BGP extract $(75 \mu \mathrm{g} / \mathrm{mL})$ was administrated to cells and allowed to co-incubate for another $12 \mathrm{~h}$. Then $2.7 \mu \mathrm{M}$ PpIX was added. After $5 \mathrm{~h}$, dishes were illuminated by laser at a power of $27 \mathrm{~mW} / \mathrm{cm}^{2}$ for $30 \mathrm{~min}$. The control group was run in parallel. The TUNEL assay was performed according to the manufacturer's instructions. Images were captured by a confocal scanning laser microscope (IX83, Olympus, Tokyo, Japan). 


\subsection{Annexin V-FITC/PI Staining Assay}

Annexin V-FITC/PI staining assay was performed to detect apoptosis. $2 \times 10^{5}$ A431 cells were first seeded to 6-well plates. After $12 \mathrm{~h}$, medium containing BGP extract $(75 \mu \mathrm{g} / \mathrm{mL})$ was administrated to cells and allowed to co-incubate for another $12 \mathrm{~h}$. Then $2.7 \mu \mathrm{M}$ PpIX was added. After $5 \mathrm{~h}$, plates were illuminated by laser at a power of $27 \mathrm{~mW} / \mathrm{cm}^{2}$ for $30 \mathrm{~min}$. The control group was run in parallel. After $2 \mathrm{~h}$ incubation, cells were harvested and stained according to the manufacturer's instructions. Detection was done by a BD Accuri ${ }^{\mathrm{TM}}$ C6 flow cytometer (Franklin Lakes, NJ, USA).

\subsection{Western Blotting Analysis}

For western blotting analysis, cells were lysed by the addition of radio immunoprecipitation assay (RIPA) lysis buffer. Protein samples were separated by SDS-polyacrylamide gel (SDS-PAGE) under reducing conditions. Resolved protein was transferred to a methanol-activated polyvinylidene difluoride (PVDF) membrane in transfer buffer. The membrane was blocked in 5\% nonfat milk for $2 \mathrm{~h}$ at room temperature. Then, the blocked membrane was incubated with the primary antibody at $4{ }^{\circ} \mathrm{C}$ overnight before the incubation with secondary antibody for $2 \mathrm{~h}$ at room temperature. Immunoreactive bands were visualized using an Immobilon Western chemiluminescent HRP substrate (Millipore, Darmstadtcity, Germany).

\subsection{Animal Experiments}

Six-weeks-old male BALB/c-nu mice, with 16-18 g, were purchased from the Model Animal Research Center of Nanjing University (Animal Certificate: SCXK Su 2015-0001) and maintained in separate cages in a specifically designed pathogen-free isolation facility with a $12 \mathrm{~h}$ light/dark cycle; the mice were provided rodent chow and water ad libitum. The xenograft tumor model was developed by inoculation of A431 cells. Cells were first seeded to 6-well plates. After $12 \mathrm{~h}$, medium containing BGP extract was administrated to cells and allowed to co-incubate for another $12 \mathrm{~h}$. Then PpIX were added and allowed to co-incubate for $5 \mathrm{~h}$. Afterwards, plates were illuminated at a power of $27 \mathrm{~mW} / \mathrm{cm}^{2}$ for $30 \mathrm{~min}$. The control was run in parallel. $3 \times 10^{6}$ cells after pretreatment of $2.7 \mu \mathrm{M}$ PpIX-PDT $\left(27 \mathrm{~mW} / \mathrm{cm}^{2}\right)$ or BGP extract $(75 \mu \mathrm{g} / \mathrm{mL})$ either alone or in the indicated combination were injected subcutaneously into the right flank of BALB/c-nu mice $(n=6)$. Tumor size were measured with vernier caliper once per day after one-week development, and tumor volume was calculated as $\mathrm{V}=\left(\mathrm{L} \times \mathrm{W}^{2}\right) / 2$, where $\mathrm{L}$ is the length and $\mathrm{W}$ is the width of the tumor. Animals were sacrificed 6 days after initial measurement and tumor weight was measured. The animal studies were carried out in accordance to conform to institutional guidelines that comply with national and international laws and policies. All animal experiments were approved by the Ethics Committee of China Pharmaceutical University.

\subsection{Intracellular Accumulation of PpIX}

Intracellular PpIX was detected by flow cytometry. A431 cells were seeded to 6-well plates. After $12 \mathrm{~h}$, medium containing BGP extract $(75 \mu \mathrm{g} / \mathrm{mL})$ was administrated to cells and allowed to co-incubate for another $12 \mathrm{~h}$. Then $2.7 \mu \mathrm{M}$ PpIX was added. The control group ran in parallel. Cells were harvested and detected by a BD Accuri ${ }^{\mathrm{TM}} \mathrm{C} 6$ flow cytometer $5 \mathrm{~h}$ later.

\subsection{Statistical Analysis}

Data were expressed as mean \pm SEM. Statistical significance was assessed by student test (nonparametric) followed by Welch's correction using GraphPad Prism 6.02 (La Jolla, CA, USA).

\section{Conclusions}

Our findings provide evidence for a synergistic effect of BGP extract in PDT. BGP extract enhances the intracellular accumulation of PpIX, attenuates inflammatory factors and increases apoptosis. Based on our findings BGP should be considered as an adjuvant in future PDT approaches. 
Acknowledgments: This work was supported by the National Natural Science Foundation of China (81402964), the Natural Science Foundation of Jiangsu Province (BK20140665), the Fundamental Research Funds for the Central Universities (ZD2014YW0029) and the College Students Innovation Project for the R\&D of Novel Drugs (J1030830).

Author Contributions: Conceived and designed the experiments: Cheng-Cheng Wang, Yu-Xuan Wang, Liang Wu, Ling He, Hao Wang; Performed the experiments: Cheng-Cheng Wang, Yu-Xuan Wang, Jing Yao, Hao Wang, Nian-Qin Yu, Die Hu, Xiao-Yan Wang, Xing-Guang Chen, You-Wei Liao; Analyzed the data: Cheng-Cheng Wang, Yu-Xuan Wang, Liang Wu; Wrote the paper: Cheng-Cheng Wang, Yu-Xuan Wang, Liang Wu, Ling He, Hao Wang.

Conflicts of Interest: The authors declare no conflict of interest. The founding sponsors had no role in the design of the study; in the collection, analyses, or interpretation of data; in the writing of the manuscript, and in the decision to publish the results.

\section{References}

1. Salatino, A.; Fernandes-Silva, C.C.; Righi, A.A.; Salatino, M.L. Propolis research and the chemistry of plant products. Nat. Prod. Rep. 2011, 28, 925-936. [CrossRef] [PubMed]

2. Simone-Finstrom, M.; Spivak, M. Propolis and bee health: The natural history and significance of resin use by honey bees. Apidologie 2010, 41, 295-311. [CrossRef]

3. Bankova, V.; Marcucci, M.C.; Simova, S.; Nikolova, N.; Kujumgiev, A.; Popov, S. Antibacterial diterpenic acids from Brazilian propolis. Z. Naturforsch. C. 1996, 51, 277-280. [PubMed]

4. Machado, J.L.; Assuncao, A.K.; da Silva, M.C.; Dos Reis, A.S.; Costa, G.C.; Arruda Dde, S.; Rocha, B.A.; Vaz, M.M.; Paes, A.M.; Guerra, R.N.; et al. Brazilian green propolis: Anti-inflammatory property by an immunomodulatory activity. Evid. Based Complement. Alternat. Med. 2012, 2012, 157652. [CrossRef] [PubMed]

5. Paulino, N.; Teixeira, C.; Martins, R.; Scremin, A.; Dirsch, V.M.; Vollmar, A.M.; Abreu, S.R.; de Castro, S.L.; Marcucci, M.C. Evaluation of the analgesic and anti-inflammatory effects of a Brazilian green propolis. Planta Med. 2006, 72, 899-906. [CrossRef] [PubMed]

6. Szliszka, E.; Kucharska, A.Z.; Sokol-Letowska, A.; Mertas, A.; Czuba, Z.P.; Krol, W. Chemical composition and anti-Inflammatory effect of ethanolic extract of Brazilian green propolis on activated J774A.1 macrophages. Evid. Based Complement. Alternat. Med. 2013, 2013, 976415. [CrossRef] [PubMed]

7. Wu, Z.; Zhu, A.; Takayama, F.; Okada, R.; Liu, Y.; Harada, Y.; Wu, S.; Nakanishi, H. Brazilian green propolis suppresses the hypoxia-induced neuroinflammatory responses by inhibiting NF- $\mathrm{kB}$ activation in microglia. Oxid. Med. Cell. Longev. 2013, 2013, 906726. [CrossRef] [PubMed]

8. Maruyama, H.; Sumitou, Y.; Sakamoto, T.; Araki, Y.; Hara, H. Antihypertensive effects of flavonoids isolated from Brazilian green propolis in spontaneously hypertensive rats. Biol. Pharm. Bull. 2009, 32, 1244-1250. [CrossRef] [PubMed]

9. Mishima, S.; Yoshida, C.; Akino, S.; Sakamoto, T. Antihypertensive effects of Brazilian propolis: Identification of caffeoylquinic acids as constituents involved in the hypotension in spontaneously hypertensive rats. Biol. Pharm. Bull. 2005, 28, 1909-1914. [CrossRef] [PubMed]

10. Koya-Miyata, S.; Arai, N.; Mizote, A.; Taniguchi, Y.; Ushio, S.; Iwaki, K.; Fukuda, S. Propolis prevents diet-induced hyperlipidemia and mitigates weight gain in diet-induced obesity in mice. Biol. Pharm. Bull. 2009, 32, 2022-2028. [CrossRef] [PubMed]

11. Nakajima, Y.; Shimazawa, M.; Mishima, S.; Hara, H. Neuroprotective effects of Brazilian green propolis and its main constituents against oxygen-glucose deprivation stress, with a gene-expression analysis. Phytother. Res. PTR 2009, 23, 1431-1438. [CrossRef] [PubMed]

12. Bufalo, M.C.; Candeias, J.M.; Sforcin, J.M. In vitro cytotoxic effect of Brazilian green propolis on human laryngeal epidermoid carcinoma (HEp-2) cells. Evid. Based Complement. Alternat. Med. 2009, 6, 483-487. [CrossRef] [PubMed]

13. Ishiai, S.; Tahara, W.; Yamamoto, E.; Yamamoto, R.; Nagai, K. Histone deacetylase inhibitory effect of Brazilian propolis and its association with the antitumor effect in Neuro2a cells. Food Sci. Nutr. 2014, 2, 565-570. [CrossRef] [PubMed]

14. Messerli, S.M.; Ahn, M.R.; Kunimasa, K.; Yanagihara, M.; Tatefuji, T.; Hashimoto, K.; Mautner, V.; Uto, Y.; Hori, H.; Kumazawa, S.; et al. Artepillin C (ARC) in Brazilian green propolis selectively blocks oncogenic PAK1 signaling and suppresses the growth of NF tumors in mice. Phytother. Res. PTR 2009, 23, $423-427$. [CrossRef] [PubMed] 
15. Frion-Herrera, Y.; Diaz-Garcia, A.; Ruiz-Fuentes, J.; Rodriguez-Sanchez, H.; Sforcin, J.M. Brazilian green propolis induced apoptosis in human lung cancer A549 cells through mitochondrial-mediated pathway. J. Pharm. Pharmacol. 2015, 67, 1448-1456. [CrossRef] [PubMed]

16. Szliszka, E.; Zydowicz, G.; Janoszka, B.; Dobosz, C.; Kowalczyk-Ziomek, G.; Krol, W. Ethanolic extract of Brazilian green propolis sensitizes prostate cancer cells to TRAIL-induced apoptosis. Inter. J. Oncol. 2011, 38, 941-953.

17. Szliszka, E.; Zydowicz, G.; Mizgala, E.; Krol, W. Artepillin C (3,5-diprenyl-4-hydroxycinnamic acid) sensitizes LNCaP prostate cancer cells to TRAIL-induced apoptosis. Int. J. Oncol. 2012, 41, 818-828. [PubMed]

18. Agostinis, P.; Berg, K.; Cengel, K.A.; Foster, T.H.; Girotti, A.W.; Gollnick, S.O.; Hahn, S.M.; Hamblin, M.R.; Juzeniene, A.; Kessel, D.; et al. Photodynamic therapy of cancer: An update. CA Cancer J. Clin. 2011, 61, 250-281. [CrossRef] [PubMed]

19. Moor, A.C. Signaling pathways in cell death and survival after photodynamic therapy. J. Photochem. Photobiol. B Biol. 2000, 57, 1-13. [CrossRef]

20. Gomer, C.J. Induction of prosurvival molecules during treatment: Rethinking therapy options for photodynamic therapy. J. Natl. Compr. Cancer Netw. JNCCN 2012, 10 (Suppl. 2), S35-S39. [CrossRef] [PubMed]

21. Milla Sanabria, L.; Rodriguez, M.E.; Cogno, I.S.; Rumie Vittar, N.B.; Pansa, M.F.; Lamberti, M.J.; Rivarola, V.A. Direct and indirect photodynamic therapy effects on the cellular and molecular components of the tumor microenvironment. Biochim. Biophys. Acta 2013, 1835, 36-45. [CrossRef] [PubMed]

22. Gollnick, S.O.; Evans, S.S.; Baumann, H.; Owczarczak, B.; Maier, P.; Vaughan, L.; Wang, W.C.; Unger, E.; Henderson, B.W. Role of cytokines in photodynamic therapy-induced local and systemic inflammation. Br. J. Cancer 2003, 88, 1772-1779. [CrossRef] [PubMed]

23. Li, D.; Zhong, Y.; Zhou, Y.; Sun, H.; Zheng, X.; Zhao, C.; Yan, Y.; Lin, Y.; Liao, L.; Wang, X. Autocrine TNF-alpha-mediated NF- $\mathrm{BB}$ activation is a determinant for evasion of CD40-induced cytotoxicity in cancer cells. Biochem. Biophys. Res. Commun. 2013, 436, 467-472. [CrossRef] [PubMed]

24. de Groot, D.J.; de Vries, E.G.; Groen, H.J.; de Jong, S. Non-steroidal anti-inflammatory drugs to potentiate chemotherapy effects: From lab to clinic. Crit. Rev. Oncol. Hematol. 2007, 61, 52-69. [CrossRef] [PubMed]

25. Greenhough, A.; Smartt, H.J.; Moore, A.E.; Roberts, H.R.; Williams, A.C.; Paraskeva, C.; Kaidi, A. The COX-2/PGE2 pathway: Key roles in the hallmarks of cancer and adaptation to the tumour microenvironment. Carcinogenesis 2009, 30, 377-386. [CrossRef] [PubMed]

26. Pikarsky, E.; Porat, R.M.; Stein, I.; Abramovitch, R.; Amit, S.; Kasem, S.; Gutkovich-Pyest, E.; Urieli-Shoval, S.; Galun, E.; Ben-Neriah, Y. NF-kB functions as a tumour promoter in inflammation-associated cancer. Nature 2004, 431, 461-466. [CrossRef] [PubMed]

27. Li, Y.J.; Zhou, J.H.; Du, X.X.; Jia de, X.; Wu, C.L.; Huang, P.; Han, Y.; Sui, H.; Wei, X.L.; Liu, L.; et al. Dihydroartemisinin accentuates the anti-tumor effects of photodynamic therapy via inactivation of NF- $k B$ in Eca109 and Ec9706 esophageal cancer cells. Cell. Physiol. Biochem. 2014, 33, 1527-1536. [CrossRef] [PubMed]

28. Song, J.; Wei, Y.; Chen, Q.; Xing, D. Cyclooxygenase 2-mediated apoptotic and inflammatory responses in photodynamic therapy treated breast adenocarcinoma cells and xenografts. J. Photochem. Photobiol. B Biol. 2014, 134, 27-36. [CrossRef] [PubMed]

29. Lisicic, D.; Benkovic, V.; Ethikic, D.; Blazevic, A.S.; Mihaljevic, J.; Orsolic, N.; Knezevic, A.H. Addition of propolis to irinotecan therapy prolongs survival in ehrlich ascites tumor-bearing mice. Cancer Biother. Radiopharm. 2014, 29, 62-69. [CrossRef] [PubMed]

30. Szliszka, E.; Czuba, Z.P.; Domino, M.; Mazur, B.; Zydowicz, G.; Krol, W. Ethanolic extract of propolis (EEP) enhances the apoptosis- inducing potential of TRAIL in cancer cells. Molecules 2009, 14, 738-754. [CrossRef] [PubMed]

31. Szliszka, E.; Czuba, Z.P.; Bronikowska, J.; Mertas, A.; Paradysz, A.; Krol, W. Ethanolic Extract of Propolis Augments TRAIL-Induced Apoptotic Death in Prostate Cancer Cells. Evid. Based Complement. Altern. Med. 2011, 2011, 535172. [CrossRef] [PubMed]

32. Granville, D.J.; Carthy, C.M.; Jiang, H.; Levy, J.G.; McManus, B.M.; Matroule, J.Y.; Piette, J.; Hunt, D.W. Nuclear factor-kappaB activation by the photochemotherapeutic agent verteporfin. Blood 2000, 95, 256-262. [PubMed] 
33. Kulikova, L.; Mikes, J.; Hyzdalova, M.; Palumbo, G.; Fedorocko, P. NF-kappaB is not directly responsible for photoresistance induced by fractionated light delivery in HT-29 colon adenocarcinoma cells. Photochem. Photobiol. 2010, 86, 1285-1293. [CrossRef] [PubMed]

34. Korbelik, M. Complement upregulation in photodynamic therapy-treated tumors: Role of Toll-like receptor pathway and NFkB. Cancer Lett. 2009, 281, 232-238. [CrossRef] [PubMed]

35. Matroule, J.Y.; Volanti, C.; Piette, J. NF-kappaB in photodynamic therapy: Discrepancies of a master regulator. Photochem. Photobiol. 2006, 82, 1241-1246. [CrossRef] [PubMed]

36. Weiss, A.; den Bergh, H.; Griffioen, A.W.; Nowak-Sliwinska, P. Angiogenesis inhibition for the improvement of photodynamic therapy: The revival of a promising idea. Biochim. Biophys. Acta 2012, 1826, 53-70. [CrossRef] [PubMed]

37. Milas, L.; Mason, K.A.; Crane, C.H.; Liao, Z.; Masferrer, J. Improvement of radiotherapy or chemoradiotherapy by targeting COX-2 enzyme. Oncology 2003, 17, 15-24. [PubMed]

38. Piette, J. Signalling pathway activation by photodynamic therapy: NF- $\mathrm{kB}$ at the crossroad between oncology and immunology. Photochem. Photobiol. Sci. 2015, 14, 1510-1517. [CrossRef] [PubMed]

39. Kaidi, A.; Qualtrough, D.; Williams, A.C.; Paraskeva, C. Direct transcriptional up-regulation of cyclooxygenase-2 by hypoxia-inducible factor (HIF)-1 promotes colorectal tumor cell survival and enhances HIF-1 transcriptional activity during hypoxia. Cancer Res. 2006, 66, 6683-6691. [CrossRef] [PubMed]

40. Luna, M.; Wong, S.; Ferrario, A.; Gomer, C.J. Cyclooxygenase-2 expression induced by photofrin photodynamic therapy involves the p38 MAPK pathway. Photochem. Photobiol. 2008, 84, 509-514. [CrossRef] [PubMed]

41. Tanabe, T.; Tohnai, N. Cyclooxygenase isozymes and their gene structures and expression. Prostag. Other Lipid Mediat. 2002, 69, 95-114. [CrossRef]

42. Saenz, C.; Ethirajan, M.; Iacobucci, G.; Pandey, A.; Missert, J.R.; Dobhal, M.P.; Pandey, R.K. Indium as a central metal enhances the photosensitizing efficacy of benzoporphyrin derivatives. J. Porphyr. Phthalocyanines 2011, 15, 1310. [CrossRef] [PubMed]

43. Anand, S.; Wilson, C.; Hasan, T.; Maytin, E.V. Vitamin D3 enhances the apoptotic response of epithelial tumors to aminolevulinate-based photodynamic therapy. Cancer Res. 2011, 71, 6040-6050. [CrossRef] [PubMed]

44. De Rosa, F.S.; Bentley, M.V. Photodynamic therapy of skin cancers: Sensitizers, clinical studies and future directives. Pharm. Res. 2000, 17, 1447-1455. [CrossRef] [PubMed]

Sample Availability: Not available.

(C) 2017 by the authors. Licensee MDPI, Basel, Switzerland. This article is an open access article distributed under the terms and conditions of the Creative Commons Attribution (CC BY) license (http:/ / creativecommons.org/licenses/by/4.0/). 